\title{
COMPUTER INTERFACED EXPERIMENTS ON EXPEYES: MEASURING ACCELERATION DUE TO GRAVITY WITH A COMPOUND BAR PENDULUM USING ULTRASONIC SENSOR
}

\author{
Dr Naveen Rawat \\ Department of Physics \\ Quantum University, Roorkee, UK, USA
}

Abstract- Use of Computer interface for data acquisition and analysis is constantly being pursued and incorporated into curriculum developed at Quantum University. Several experiments at Introductory level for Science and Engineering students have already been successfully modernized, tested and implemented in the curriculum. Devices such as the ExpEyes, that offer flexibility in designing experiments, have been well received by the students and help them be better prepared for the real world technologies after graduation.

In this paper, we describe alternate experimental setups for measurement of acceleration due to gravity of a Compound Bar Pendulum using ExpEyes that allows us to measure and analyze the data on a computer. The experimental analysis clearly shows that using the Ultrasonic sensor gives reliable and excellent results and proves to be an effective technique for achieving student learning outcome.

Keywords- Ultrasonic sensor, ExpEyes, Compound Pendulum, Acceleration due to Gravity, Undergraduate, BSc Experiments.

\section{INTRODUCTION}

With the use of computer based technologies in industries worldwide, new doors have been opened for enhanced learning by modernization of experiments, computer interfaced data collection and subsequent analysis[1,2] It is quite inevitable that more and more of the traditional measurement techniques for physics majors will be updated for more effective teaching and learning outcomes [3,4]. In this regard we present our work on couple of alternative methods to perform the typical experiment for measurement of Acceleration due to gravity with a Bar pendulum by use of ultrasonic motion sensor. This experiment is usually part of the introductory mechanics course in many universities and our own. The experiment is interfaced with computer using ExpEyes device developed by Ajith et al. (2009) and entire data analysis was performed on softwares such as Excel,

\author{
Divyansh \\ Department of Physics \\ Quantum University, Roorkee, UK, USA
}

Grapher and Desmos which are readily available for use in a lab setting.

\section{BACKGROUND}

Oscillatory motion is quite common occurrence from a boat swaying in the sea, child playing on a swing, to the vibration of a molecule or an atom $[5,6]$. Study of pendulum motion in a lab setting gives one the opportunity to get acquainted with this important phenomena in detail. A simple pendulum is not ideal when it comes to measurement of acceleration due to gravity as approximations are made related to mass of thread used to hang the bob and amplitude and motion of the bob. A Compound Bar Pendulum provides much more accurate results as it is applicable to body of any shape oscillating about the known axis [7-10]. The Bar Pendulum used in undergraduate physics labs consists of a uniform rectangular metal bar $(100 \mathrm{~cm} \mathrm{x} 4 \mathrm{~cm}$ $\mathrm{x} 0.6 \mathrm{~cm}$ ) with several holes drilled along its length such that the holes pass through the centre of gravity. The known time period of the bar pendulum of length $l$ and radius of gyration $k$ is

$$
T=2 \pi \sqrt{\frac{k^{2}+l^{2}}{l g}}
$$

If the effective length, $L$ is

$$
L=\frac{k^{2}+l^{2}}{l}
$$

Then acceleration due to gravity, $\mathrm{g}$ can be written as

$$
g=\frac{4 \pi^{2} L}{T^{2}}
$$

Simplifying equation 3 in 2 one can rearrange the equation in the form

$$
l^{2}=g \frac{I T^{2}}{4 \pi^{2}}-K^{2}
$$

Hence, one can calculate the value of acceleration due to gravity, $\mathrm{g}$ by measuring different time periods for different 


\section{International Journal of Engineering Applied Sciences and Technology, 2020 Vol. 5, Issue 3, ISSN No. 2455-2143, Pages 451-454 \\ Published Online July 2020 in IJEAST (http://www.ijeast.com)}

lengths of the pendulum by changing the point of suspension. The practical lab for bar pendulum when computer interfaced gives the opportunity to do accurate measurements and handson experience with more skills such as data fitting and use of sensors. For this purpose ExpEyes is ideal toolkit to get this implemented as it is easy to use and already widely being applied [11-15]

All additional information for analysis and data is present in the Appendix Section

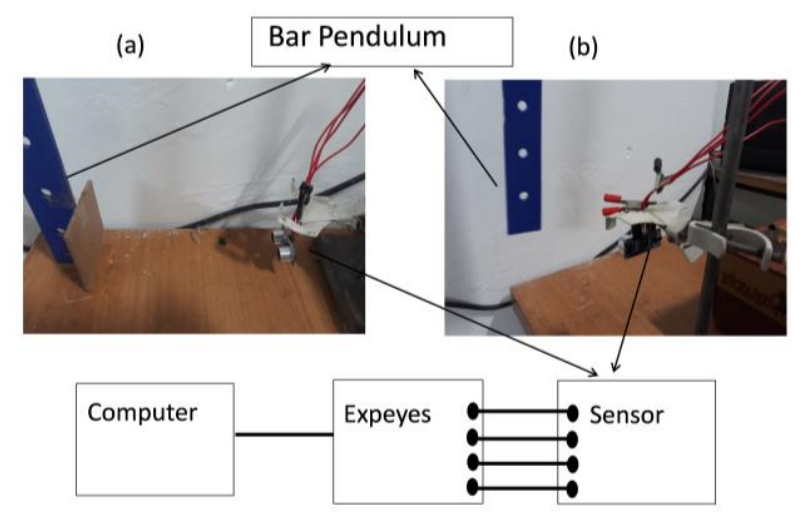

Fig. 1. (a) Board Echo measurement setup with sensor on the side of the pendulum reflecting the echo from a flat board b) Wall Echo measurement setup with sensor in the front of the pendulum. The wall acts a fixed background with pendulum obstructing the signal every time it oscillates in front of the sensor.

\section{A. Board Echo Measurement Technique-}

One alternative method to measure the time period of a compound pendulum is by using an ultrasonic sensor placed along the side of the Bar pendulum that reflects a signal of a flat board $(8 \mathrm{~cm} \times 8 \mathrm{~cm})$ attached to side of the rectangular bar pendulum (see figure 1(a)). The distance vs time response of the sensor should itself represent a simple harmonic motion (sine curve) that can fitted using a sine function to directly find the frequency of the oscillation. Inverse of the frequency will give us the time period of each oscillation corresponding to the length of the pendulum. The length of the pendulum is changed for every run by choosing the point of suspension $l=$ $45 \mathrm{~cm}$ to $l=5 \mathrm{~cm}$.

\section{B. Wall Echo Measurement Technique-}

Another alternative method is to use a reference reflection for example from a wall behind the bar pendulum with the sensor fixed in front of the pendulum (see figure 1(b)). The sensor will measure the fixed position of the wall in continual mode and every time the pendulum swings in front of the sensor, it will record the distance between the sensor and the pendulum. Therefore one can use the peak to peak distance between the obstruction caused by the pendulum and if we measure the time for one complete cycle (pendulum will swing by twice) one can calculate the time period.

\section{EXPERIMENT AND RESULT}

The measurements in both the cases mentioned earlier were done by interfacing the sensor HCSR04 module to the Expeyes device and recording the distance vs time response using the inbuilt program feature in the Expeyes program. Using the values of time period and length $l$, one can plot a graph of $l^{2}$ vs $l \mathrm{~T}^{2}$ to extract the acceleration due to gravity (see equation 4 ). Equation 4 is of the form of an equation of a line and hence the slope of the curve is extracted by fitting the data to the equation of a line. Acceleration due to gravity is $4 \pi^{2}$ times the slope and one can also extract the radius of gyration, $\boldsymbol{K}$ by using the intercept value of the equation.

\section{A. Board Echo Results -}

The experimental results for compound pendulum using Board Echo technique are summarized in Table 1. Figure 2(a) shows the simple harmonic response of the $l=5 \mathrm{~cm}$ suspension run which has a corresponding frequency of $0.37 \mathrm{~Hz}$ and time period of 2.703 seconds. The corresponding frequencies from sine curve fittings for all the different suspension lengths are shown in Table 1. For additional data related to the experiment, please see Appendix section at the end.

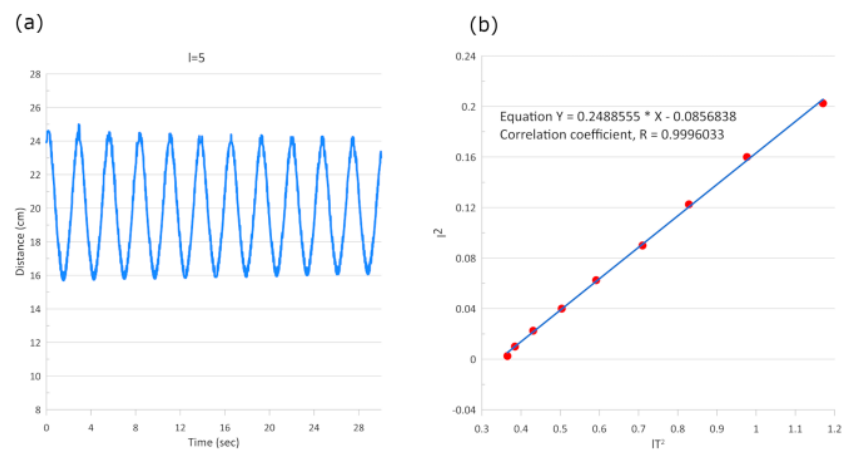

Fig. 2. (a) Simple Harmonic Curve measured for the case of suspension length of $5 \mathrm{~cm}$ of the pendulum. b) $l^{2}$ vs $l T^{2}$ plot with fitted equation of a line to extract the slope and intercept. Acceleration due to gravity is extracted using the slope and Radius of gyration is extrapolated using intercept.

The simple harmonic data is analyzed and is shown in figure 2 , where in the fitting of the curve gives us the equation of a line. The value obtained for acceleration due to gravity is 9.81 $\mathrm{m} / \mathrm{s}^{2}$ and radius of gyration, $\mathrm{K}=29.2 \mathrm{~cm}$ As expected the time period varies with length 1 of the pendulum and time period is minimum which corresponds to the condition when its length is equal to its radius of gyration i.e. $1=\mathrm{k}$. 


\section{International Journal of Engineering Applied Sciences and Technology, 2020 Vol. 5, Issue 3, ISSN No. 2455-2143, Pages 451-454 \\ Published Online July 2020 in IJEAST (http://www.ijeast.com)}

Table -1 Experiment Result of Board Echo measurements

\begin{tabular}{|l|l|l|l|l|}
\hline $\begin{array}{l}\text { Distance l of the } \\
\text { suspension from one } \\
\text { end }(\mathrm{cm})\end{array}$ & $\begin{array}{l}\text { Frequency } \\
\text { from fit } \\
(\mathrm{Hz})\end{array}$ & $\begin{array}{l}\text { Time } \\
\text { Period } \\
(\mathrm{sec})\end{array}$ & $\begin{array}{l}l^{2} \\
\left(\mathrm{~m}^{2}\right)\end{array}$ & $\begin{array}{l}l \mathrm{~T}^{2} \\
\left(\mathrm{~ms}^{2}\right)\end{array}$ \\
\hline 45 & 0.62 & 1.613 & 0.203 & 1.209 \\
\hline 40 & 0.64 & 1.563 & 0.160 & 0.977 \\
\hline 35 & 0.65 & 1.538 & 0.123 & 0.828 \\
\hline 30 & 0.65 & 1.538 & 0.090 & 0.710 \\
\hline 25 & 0.65 & 1.538 & 0.063 & 0.592 \\
\hline 20 & 0.63 & 1.587 & 0.040 & 0.504 \\
\hline 15 & 0.59 & 1.695 & 0.023 & 0.431 \\
\hline 10 & 0.51 & 1.961 & 0.010 & 0.384 \\
\hline 5 & 0.37 & 2.703 & 0.003 & 0.365 \\
\hline
\end{tabular}

\section{B. Wall Echo Results -}

The experimental results for compound pendulum using Wall echo measurements are summarized in Table 2. The time period varies with length $l$ of the pendulum and time period is minimum which corresponds to the condition when its length is equal to its radius of gyration i.e. $k$. The distance vs time response of the $l=5 \mathrm{~cm}$ suspension run of compound pendulum is represented in the figure 3(a). The average time period of 2.76 seconds was calculated by measuring time period between three random oscillations and then averaging them (see Appendix Table 3). The average time period from peak to peak for an entire cycle for all the suspensions is shown in the Table 3. For additional data related to the experiment please see Appendix Figure 5. (a)

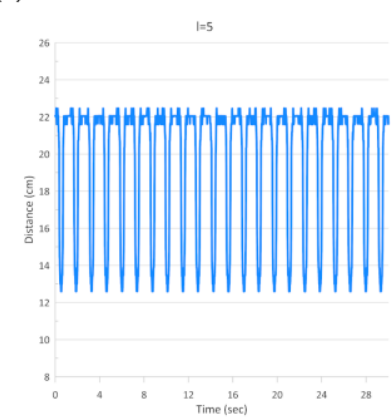

(b)

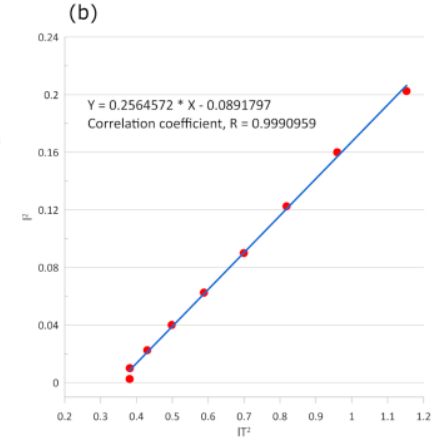

Fig 3. (a) Distance vs time response measured for the case of length of $5 \mathrm{~cm}$ of suspension from the pendulum. The peak to peak time for an entire cycle is measured from the curve. b) $l^{2}$ vs $l T^{2}$ plot with fitted equation of a line to extract the slope and intercept. Acceleration due to gravity is extracted using the slope and Radius of gyration is extrapolated using intercept.
The Wall echo data analysis is shown in figure 3(a) where in the fitting of the curve gives us the equation of a line. The value obtained for acceleration due to gravity is 10.12 $\mathrm{m} / \mathrm{s}^{2}$ and radius of gyration, $\mathrm{K}=29.9 \mathrm{~cm}$

Table -2 Experiment Result of Wall Echo measurements

\begin{tabular}{|l|l|l|l|}
\hline $\begin{array}{l}\text { Distance l of the } \\
\text { suspension from one } \\
\text { end }(\mathrm{cm})\end{array}$ & $\begin{array}{l}\text { Time } \\
\text { Period } \\
(\mathrm{sec})\end{array}$ & $\begin{array}{l}l^{2} \\
\left(\mathrm{~m}^{2}\right)\end{array}$ & $\begin{array}{l}l \mathrm{~T}^{2} \\
\left(\mathrm{~ms}^{2}\right)\end{array}$ \\
\hline 45 & 1.600 & 0.203 & 1.152 \\
\hline 40 & 1.563 & 0.160 & 0.959 \\
\hline 35 & 1.538 & 0.123 & 0.818 \\
\hline 30 & 1.538 & 0.090 & 0.699 \\
\hline 25 & 1.538 & 0.063 & 0.588 \\
\hline 20 & 1.587 & 0.040 & 0.498 \\
\hline 15 & 1.695 & 0.023 & 0.430 \\
\hline 10 & 1.961 & 0.010 & 0.381 \\
\hline 5 & 2.703 & 0.003 & 0.381 \\
\hline
\end{tabular}

\section{CONCLUSION}

The results clearly show that the Board Echo measurement gives us the reliable and accurate results of the Acceleration due to gravity. Moreover, the data that is recorded as a Simple harmonic curve is a much better representation of the technique and presents the opportunity for students to relate to the concept better. There is less noise in the data from the technique as seen apparent in difference of Appendix figure 4 and figure 5. We would also like to draw your attention to the fact that the Wall Echo technique is much more cumbersome for evaluation of the time periods and hence may be avoided in the lab setting. The experiments performed here surely validate the importance of using computer interface to perform introductory physics experiments and we hope to continue along these lines to incorporate more experiments like these in the student curriculum.

\section{ACKNOWLEDGEMENT}

The authors would like to thank Dr. Ajith Kumar and Mr. V V V Satyanarayana at IUAC Delhi for the workshop and training on ExpEyes device. The exposure was invaluable and has directly led to the outcome of current work presented in this paper.

\section{REFERENCE}

[1] Ajith Kumar B. P. and Satyanarayana V. V. V. and Singh K. and Singh P (2009): Innovative Science Experiments using Phoenix, Physics Education, Vol.44, No. 5, 469-473

[2] Raju A. B., Itagi A., Angadi S., Sushma V. and Shettar A. (2015): A Low Cost Open Source Hardware Tool for Integrated Learning Experience in Laboratories, Journal 


\section{International Journal of Engineering Applied Sciences and Technology, 2020 \\ Vol. 5, Issue 3, ISSN No. 2455-2143, Pages 451-454 \\ Published Online July 2020 in IJEAST (http://www.ijeast.com)}

of Engineering Education Transformations, eISSN 23941707

[3] Vaidya O.S., Jane M., Mahale A. (2016): Review on Implementation of Analog Circuits using Expeyes tool, Vol. 1, Issue 12, ISSN No. 2455-2143, Pages 29-31

[4] Haldankar G.T., Vashi H., Sarode J. (2016): Audio Frequency Analyzer Using ExpEYES and Raspberry pi

[5] Tipler Paul A. and Mosca G. (2004): "Physics for Scientists and Engineers" W.H. Freeman and Company Ny, Extended fifth edition

[6] Ohanian Hans C. and Markert John T. (2007): "Physics for Engineers and Scientists" W.W. Norton and Company Inc. Third Edition

[7] Arora C. L. (2008): B.Sc practical physics (S . Chand publication, 21st edition.

[8] Pathare S.R., Lahane R.D., Sawant S.S., Patil C.C. (2012): Compound Pendulum,Homi Bhabha Centre for Science Education(TIFR), Vol. 28 Issue 3 , article:5

[9] Shukla, R.K. Srivastava A.: Practical physics, NEW Age international $(\mathrm{P})$ limited,publishers

[10] Pedersen, N. F., and Sørensen, O. H. (1977). The compound pendulum in intermediate laboratories and demonstrations. American Journal of Physics, 45(10), 994-998.

[11] Nesimi Ertugrul N. (1998): “ New Era in engineering expreiment:An integrated and interactive teaching /learning approach and real time visualisation", International Journal of engineering education, Vol.14, No.5, pp 344-355,

[12] Maryam K(2014): EM induction experiment to determine the moment of a magnet, Physics Education ,Vol.49(3) ,pp 319-325.

[13] Pathra T. (2013): Optical Sensor using Expeyes Junior Kit, International Journal of Innovations in Engineering and Technology (IJIET), Vol. 3, Issue 2

[14] Thottoli, A. K., Fayis M., Mohamed T. C., Amjad T., Shameem P.T. and Mishab M. (2019) SN Applied science

[15] Luthra V., Kaur A., Saini S., Jaglan S., Dhasmana S., Apoorva and Ajith B.P. (2016) : Evaluation of Boltzmann's constant-Revisit using interface data, Physics Education, Vol.32, issue 3, Article number.2.

\section{APPENDIX}

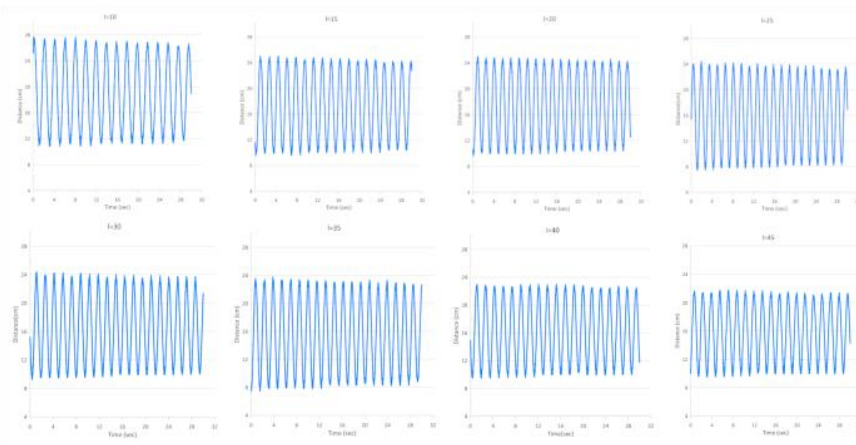

Fig. 4. Simple harmonic data from Board Echo measurement for various lengths $l$ of the bar pendulum

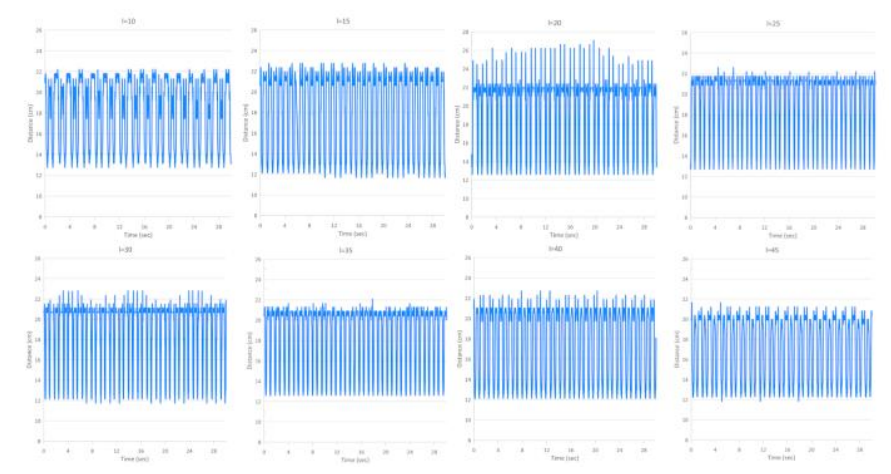

Fig. 5. Wall Echo measurement data for various lengths, $l$ of the bar pendulum.

Table -3 Calculation data extracted from the Wall echo measurement to measure the time period for various lengths, $l$ of the pendulum

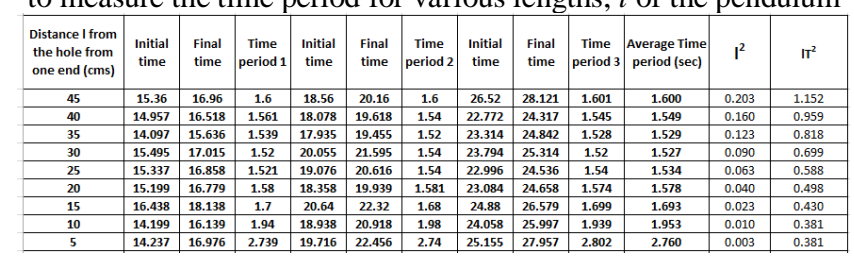

